Portland State University

PDXScholar

\title{
What's On Your Mind? : A Generational Comparison of Language Use on Online Social Networking Platforms
}

Samantha Stidham

Portland State University

Follow this and additional works at: https://pdxscholar.library.pdx.edu/honorstheses

Let us know how access to this document benefits you.

\section{Recommended Citation}

Stidham, Samantha, "What's On Your Mind? : A Generational Comparison of Language Use on Online Social Networking Platforms" (2014). University Honors Theses. Paper 70.

https://doi.org/10.15760/honors.43

This Thesis is brought to you for free and open access. It has been accepted for inclusion in University Honors Theses by an authorized administrator of PDXScholar. Please contact us if we can make this document more accessible: pdxscholar@pdx.edu. 
What's on your mind? A generational comparison of language use on online social networking platforms

by

\section{Samantha Stidham}

An undergraduate honors thesis submitted in partial fulfillment of the requirements for the degree of

\section{Bachelor of Arts}

in

University Honors

and

Applied Linguistics

Thesis Adviser

Steven L. Thorne

Portland State University 
Since the advent of the Internet, it has been a tool with many different uses: perhaps most importantly, it has been a tool for communication. From the beginning, the Internet connected people, regardless of the distance between them. It connected people through the earliest incarnations of the ARPANET, to email, to modern forms of synchronous chat—chat rooms and instant messengers. However, in 2002, computer-mediated communication changed drastically with the invention of Friendster, a social networking website (SNS) intended for use finding romantic partners. Competitors sprung up quickly, including one of the biggest platforms of early online social networking: MySpace, launched in 2003. LinkedIn, an online social network marketed at business professionals, followed. Not long after, the current best-known SNS launched at Harvard University: Facebook. The rest is history, and at the rate online social networking is growing and changing, history is made every day. Though online social networking in general will be referenced throughout this paper, the main analysis will take place about Facebook, as it is still the most widely used online social networking site as of 2014.

Compared to other fields, research on online social networking platforms is still in its infancy. Though scholars have followed the growth and changes of the networks, they change so quickly that it becomes difficult to keep up. Most research on SNSs deals with frequency of use and demographics of users (and what their preferred platforms are), along with some research on the content of their posts. This is all invaluable research, especially now that businesses have begun to tap into online social networks to better engage with their customers. The question of this paper, though, goes to the base level of that engagement: the language.

In addition to language, there is another factor to consider: the age group the users in question belong to. Though traditionally online social networking is portrayed as being a 
teenager's world, the number of adults and seniors using SNSs has grown astronomically in the last 5 years. Currently, around 45\% of Internet users age 65 or older now use Facebook, up from 35\% in late 2012 (Duggan \& Smith, 2013). There is no question that these different age groups use language differently in their daily lives, and my hypothesis is that online social networking is no exception. In this thesis, I seek to analyze the differences in language use by generation, or age group, on online social networking platforms. This analysis will take place as a literature review of relevant research on the subject, drawing from the fields of theoretical linguistics, applied linguistics, and psychology.

\section{A Brief History of Online Communication}

Before delving into the online social networking tools in popular use today, we must situate ourselves in the framework from whence they came. As previously mentioned, since its creation, the Internet has been a tool with many purposes, but with infinite possibilities in regards to communication. Though one could (and many scholars have) start as far back as Marconi and his radio waves or Bell's telephone in relating technology to communication, for our purposes it should be sufficient to start in 1957 with the Eisenhower-era Advanced Research Projects Agency. ARPA was created in the wake of Sputnik's launch, at a time when the United States seemed to be falling behind other world powers in matters of science and technology (Kleinrock 2008).

Within ARPA was the Information Processing Techniques Office, and within the IPTO was J.C.R. Licklider: Licklider imagined a "galactic network," one where computers could be connected to a "universe of information." Kleinrock — an early influence on the Internet during 
his time at Massachusetts Institute of Technology—writes in his 2008 piece History of the Internet and its flexible future, several threads occurring simultaneously in different areas of the world merged to form the bones of the Internet. Scientists from MIT, IPTO, ARPA and NPL in the United Kingdom all contributed ideas and programming to build the basics of what became the ARPANET. ARPANET began to come to fruition in 1967, and the first user-to-user transmission took place in October 1969 (Kleinrock 2010). Communication would never be the same.

Compared to today's Internet, ARPANET was rudimentary, but Internet-mediated communication expanded rapidly after its release. In 1972, Ray Tomlinson introduced e-mail ${ }^{1}$. In the same year, public demonstrations of ARPANET were conducted in Washington, D.C. In 1981, IBM released the first personal computer, the first instance of such technology being readily available to civilians. A National Research Network is proposed in 1988 , followed by the proposal of the World Wide Web in 1989.

Skipping forward by a few years, the Netscape browser was released in 1994 and made public in 1995; Bill Gates of Microsoft issued a memo titled "The Internet Tidal Wave," and the dot-com bubble began to grow. In 1996, more email was sent than postal mail, a tangible sign that Internet-mediated communication was becoming a staple of everyday American life. In 1998, blogs began to appear and the blogging platform LiveJournal launched (boyd \&Ellison 2008), forming a style of communication completely unique to the Internet. In 2001, English slipped out of its majority-language position on the Internet, falling to a 45-percent share (Kleinrock 2010).

\footnotetext{
${ }^{1}$ All timeline dates in this section come from Kleinrock 2008 unless otherwise noted.
} 
As the Internet grew into its own — and make no mistake, it is still growing and changing at present—websites devoted to online socialization began to crop up, attracting users by the thousands. In their 2008 piece Social network sites: Definition, history, and scholarship, boyd and Ellison define online social networking websites as "web-based services that allow individuals to (1) construct a public or semi-public profile within a bounded system, (2) articulate a list of other users with whom they share a connection, and (3) view and traverse their list of connections and those made by others within the system." SixDegrees.com, launched in 1997, was the first SNS released to completely fit this definition. Other websites existed with some aspects of online social networking—-for example, AsianAvenue and BlackPlanet, both released in 1998, and MiGente, released in 2000, brought users together on the premise of connecting with others of their same ethnicity, but interactions were more forum-type (boyd \& Ellison 2008). LiveJournal, also released in 1998, contained some features of boyd and Ellison's definition, but was used more as a blogging platform with some forum-type community interaction.

Perhaps the most significant innovation in this nascent stage of online social networking was the release of Friendster, launched in 2002. Initially, Friendster intended to compete with Match.com, a popular online dating service still in existence today. Rather than connecting users with strangers, as Match.com tended to do, Friendster operated on the concept that better relationships would be made by matching people with friends-of-friends. Friendster grew rapidly, and that growth caused problems for its user base: overloaded servers sometimes caused the site to crash, and as the site got bigger users were forced to confront employers and former friends and romantic partners in their circle. Friendster also alienated parts of its user base by 
maintaining stringent profile restrictions that excluded bands and "joke" or parody profiles made in the images of celebrities or institutions (boyd \& Ellison 2008).

More and more users began to feel like they couldn't see eye-to-eye with Friendster, and other SNSs were able to capitalize on the users leaving in droves. The next milestone in the story of online social networking, for the purposes of this brief history, is MySpace, launched in 2004. MySpace seemed to endorse what Friendster would reject; bands were welcomed, minors were allowed (teens began joining MySpace in hordes in 2004), and users were allowed to use HTML and CSS programming languages to personalize the look of their profiles. These differences between the two SNSs made using MySpace a more user-centric experience, and users appreciated it. At its peak, MySpace had over 100 million global users (Barnett 2011).

Scholar danah boyd has focused much of her research on the use of SNSs, particularly by teens. She has done a considerable amount of research on the ways teens use MySpace (or rather, used MySpace, as it has fallen out of favor), and how they interpreted privacy on MySpace. In its original forms (MySpace has greatly changed in its eight years) users had the option to display their profile publicly, or to make their profile private to all but those users they designated as "Friends."2 Users could fill out a detailed profile in order to share details about their lifeeducation, workplace, favorite books and movies, etc. - and then publish that profile, either to their Friends list or publicly. MySpace also allowed users to post on each others' profiles, a service currently available on Facebook in a slightly different form. MySpace also featured a private messaging service; being asynchronous, this service was closer to email than an instant messaging experience.

\footnotetext{
${ }^{2}$ In this paper, I will use danah boyd's convention of referring to the online social network connection of two users as Friends, and the in-person social connection of two people as friends.
} 
danah boyd has followed the social networking boom from its origins. As mentioned above, much of her research focuses on the different ways teens use online social networking platforms. In her 2008 piece Why Youth [Heart] Social Network Sites, she introduces the idea that teens are so incredibly active online because modern parenting styles keep them on a very tight leash. Teens and young adults, according to boyd, have been instrumental in the development and continued use of online social networking sites. Later in this thesis, boyd's work will be analyzed further in a discussion of the differences in the ways teens use SNSs versus adults.

On the heels of the inclusivity of MySpace, a more tightly-knit community began to arise in the form of "the Facebook" at Harvard University. Ownership and creation of Facebook is hotly contested. As this thesis is not an exploration of that tangled web, we'll go with the official version: Mark Zuckerberg, Harvard student, created the network as a way for Harvard students to connect online. A requisite for membership of the community was having a @harvard.edu email address. The service slowly grew as all university students with a .edu email address were allowed to join; next, high school students were allowed to form networks; and finally, Facebook as it stands today was released—open to anyone and everyone over the age of 13 . These last changes also did away with much of Facebook's "closed" network mentality. For much of Facebook's existence, users could only connect based on their shared network; now, Facebook users can become Friends with anyone they choose. Users can, however, manipulate their privacy settings so that only users with whom they have mutual Friends can request to become their Friend. 
When Facebook was first released to Harvard students, its basic features were much the same as the staples of the service today. Users were able to create a profile, connect with other students at their school by searching for other students' profiles, and were able to "friend" other students by adding them to their social network. Users could then view their friends-of-friends, and were able to extend their social network this way. When it was first released, users could send private messages to one another, but communication was not synchronous; at that point, the service was more like email and not unlike the messaging feature included on MySpace. Seven months after its initial release, the "Wall" feature was added to Facebook, changing the options users had to communicate with one another by allowing users to post on each others' profile pages (posts that were visible to other users). A "Groups" feature was also added, allowing users to create user-interest groups and invite their friends to join.

Facebook's next step was to allow anyone with a university email address to access the service. Networks were still restricted to students at the user's own school; no other profiles could be viewed. Facebook's features stayed fairly stable throughout this early period of development - the Wall being the main platform on which users interacted. In 2005, Facebook opened its doors to high school networks, followed by a 2006 addition of a high school version of the website. In the same year, Facebook grew and diversified once more when it began allowing anyone over the age of 13 to create a profile. During this time, Facebook made it easier to connect with people outside your designated high school or university network.

In 2005 and 2006 respectively, Facebook introduced perhaps its most essential features to this day: Photos (giving users the option to upload their photos and "tag" friends in them) and News Feed, which populated the user's homepage with text and photo updates on what their 
Friends were posting. In the next section, I discuss the features of Facebook as we know it today; later, I discuss how those features impact communication between users.

\section{Defining Facebook Today}

To understand why users make the language choices they do on Facebook, it will be useful to build a framework of understanding of the service and its current features. Compared to its earlier forms, Facebook offers updated versions of classic features, along with many other additions. They have also expanded greatly into the mobile computing field, with Facebook applications for Apple's iOS, Google's Android, and other handheld operating systems.

One of the main functions of Facebook that has been a long-running feature is the ability to create and maintain a detailed personal profile for others in your social network to view. In the early stages of Facebook, users were able to complete an "Information" section that contained information such as their hometown, favorite books and movies, political views, interests, and a free-form "About Me" section. These sections have remained largely the same throughout Facebook's lifespan, though in the current profile format (called "Timeline") they are displayed as a bar on the left side of the page of the user's profile rather than in a separate page entirely. What were once simple hyperlinks to the user's favorite books or movies are now images that link to those books' and movies' Facebook "Pages"-pages similar to individual user profiles that are created for use by bands, celebrities, and other public figures.

In conjunction with the creation of a detailed personal profile, another main long-running feature of Facebook is being able to connect with—or "Friend"—other users. To be Friends with another user on Facebook, one user must initiate the contact by requesting to be the other user's 
Friend. The user can then accept, deny, or ignore this request. If the user accepts the request, both users can now view all information, photos, and updates on each other's profiles (excepting things that a user may have hidden using Facebook's detailed privacy settings). A notable exception to Friending on Facebook is connecting with Pages, rather than individual profiles. Pages were introduced as an answer to the problem of bands, parody accounts, and similar situations rejected by Friendster and wholeheartedly accepted by MySpace. Instead of Friending a Page, a user can only "Like" the page, which adds it to an appropriate interests section in their profile and allows the user to receive updates posted by the managers of the Page. The act of "Liking" and its implications for communication will be discussed later on in this paper.

From their profile, users can write what are called "status updates." Originally, these updates were prompted by “[user] is...”, encouraging the user to write their status in third person. Starting in 2009, these prompts would rotate randomly and include the user's name, including such phrases as "How are you doing, [user]?" or "How's it going, [user]?" (Lafferty 2012) These status prompts encouraged users to write their status in first person. Some people found this personalized feature a bit unnerving. These personalized prompts have since been phased out in 2013, replaced by the more general and consistent "what's on your mind?"

Status updates are a popular feature of Facebook because they allow the user to quickly share their thoughts and feelings (or other information) with a large group of connected users all at once. Once they post the status update, it appears on the "News Feed" of their Friends. This contrasts with messages posted on Facebook's original "Wall" service, followed by the introduction of "Timeline"3 and instant messaging services, which are semi-public (Wall/

\footnotetext{
${ }^{3}$ Both features are discussed in detail in a later section.
} 
Timeline) and private (messaging). In newer incarnations of Facebook, users are able to attach photos, videos, and links to their status updates. They are also able to "tag"4 Friends in status updates, which then links to the profile of the tagged person and also notifies the person in question that they have been tagged. Later on in this paper, the ways users of different ages use language in their status updates will be discussed.

Posting photos has become such an essential feature of Facebook that it is hard to view it as a separate application, though technically it still exists as such, titled "Photos." Users can create huge albums of photos, with unlimited storage space, the only limitation being the lessthan-ideal resolution that Facebook uses to resize users' photos. Users have the option to add incredibly detailed information to their photos; they can geo-tag them using a GPS location service, add the name of the place, the date, and the time down to the minute that the picture was taken. As mentioned before, they can also tag their friends in photos; then, when a user moves their cursor over the photo, squares appear around the faces in the photo accompanied by the person's name, and if applicable, a link to their Facebook profile. Facebook has gone so far as to add facial recognition software to aid in tagging photos. As of 2010, when photos are uploaded by a user, Facebook has the capability to identify faces in a photo and to suggest users in the uploading user's Friends list who have a similar face to faces in the newly uploaded photo (Mitchell 2010).

In addition to Facebook's own Photos application, they acquired the popular social networking platform Instagram in 2012. The acquisition allowed Facebook to maintain its

\footnotetext{
${ }^{4}$ Different from tagging photos, which is discussed in a later section.
} 
dominance as the most-used photo sharing SNS, and neutralize the threat of Instagram taking over online and mobile photo sharing (Raice \& Ante 2012).

Another main feature of Facebook that has endured (albeit in slightly different incarnations) is what is now called the "News Feed." The News Feed is the page first accessed by the user upon logging into Facebook. The News Feed displays what Facebook calls "Stories"- essentially, whatever the user's Friends have recently posted. This could include status updates, photos, videos, links, etc. The News Feed also displays advertisements. Facebook-related apps, games, and products are advertised, as well as other consumer advertising. Posts from Pages (for celebrities, musicians, and other public figures), also appear in the News Feed.

The "Groups" feature of Facebook has been present in one form or another since Facebook's launch. Originally, it was a way to create online interest groups, not unlike forumbased interaction on other websites. Groups had a title, profile photo, and users could be assigned management roles within the group. This feature fell out of favor as other features were introduced to Facebook, namely the Pages feature. Groups still exist on Facebook, and differ from Pages fundamentally in that they can be closed to all users except those invited to the group. As Groups fell in popularity in comparison to Pages, Facebook introduced another groups feature - "Friend Groups." Friend Groups allow users to separate their Friends list into groups to which they can apply customized privacy settings. Many users use this feature to separate colleagues, family, and friends into groups; the ability to manipulate privacy settings for each group (and even down to the individual user) allows users to feel like they aren't offending one particular user or group of users when they share a post on Facebook. Friend Groups also 
provide the option of creating a group titled Close Friends; when users are added to this group, the adding user can view that News Feed and be privy to virtually every interaction users they've marked as Close Friends have on Facebook. Users marked as Close Friends are not notified when they are added to one of these lists. Future research on the topic of how Friend Groups affect linguistic and psychological aspects of Facebook use would be extremely useful. The importance of future research on this topic will be discussed further in the conclusion of this paper.

An integral part of the News Feed is how the user can interact with posts. When a post is viewed, be it a status update, photo, video, link, etc., users have the option to comment on it or click the "Like" 5 button. Liking a post is an easy way for a user to interact, and communicate with other users, without spending too much time or getting too specific with their response. Users can leave their thoughts, whether by Like or by comment, on any type of story shared by a user on their friends list. Liking posts has become a very easy, non-threatening way to interact with another user on Facebook. Facebook describes Liking as “....making a connection.” (Facebook 2014). Social media tracking website Brandwatch describes in a blog post the "real" reasons users Like posts as follows: "1. They find it funny. 2. They agree with what is being said. 3. They appreciate it in some way. 4. They are a fan of it. 5. They like it" (Soar 2011). However, these reasons can prove difficult to navigate when users post negative or sad updates on their Facebook profiles; then, a Like from another user meant to be in solidarity and support of the user posting a negative update could be misconstrued as finding humor in their

\footnotetext{
${ }^{5}$ As with the concept of Friend/Friending, "Like" in the context of Facebook will appear capitalized throughout this paper.
} 
misfortune. More research should be done on the exact ways users use and perceive Likes as they communicate via Facebook.

Facebook has different algorithms to determine what Stories will show up in a user's News Feed at a given time. Users are given the option to display "Top Stories," "Most Recent," or "All Friends." Selecting the Top Stories option shows users posts only from users they have designated as "Close Friends" or another similar Friend group, or Friends that the user interacts with regularly. Top Stories also displays Stories from across Facebook (from Pages or news outlets) that have been interacted with heavily by users in the viewing user's networks, region, or Facebook as a whole. "Most Recent" displays Stories that have been posted recently, by users that the viewing user has interacted with, though this option does not restrict what Stories are shown (based on who the user interacts with) as heavily as the Top Stories option. The "All Friends" option shows the viewing user stories from all Friends in their Friends list, chronologically, without taking into account how much the viewing user interacts with those users.

The last two features of Facebook I'd like to briefly define are the features that are based most heavily in user-to-user communication — the Timeline and Facebook's messaging service. Timeline, which was introduced in 2011 and replaced the Wall in 2012 (Facebook 2011), displays a user's information chronologically in terms of "Life Events." The information can be chronological from the time the user registered with Facebook, or if the user chooses, events from earlier in their life can be added, and will display as such. Users can post messages to each other on their respective Timelines, just as they could when Facebook was still calling it the Wall. These posts are only displayed on the user's Timelines, but are actually semi-public, as 
they do show up in the News Feed (who they show up to is determined by algorithms and the specific privacy settings of each user) and can be viewed by other users visiting the Timeline page of the users in question. More recently, the back-and-forth, or "Wall-to-Wall" of Facebook past has been replaced by a "Comments" feature beneath every Timeline post. As such, one user can begin a semi-public conversation with another user via a Timeline post, but those users can continue their conversation in the Comments section rather than posting back and forth on each others' Timelines.

Facebook has also always offered some form of private messaging service. Their messaging service is unique in that it seems to bridge the gap, or co-exist, as both a synchronous and asynchronous chat service. Chats can exist in a full-page window, or as a sidebar/bottom-ofscreen chat tab that can be easily minimized. However, users can receive messages when they are away from Facebook and respond to them at any time. More recently, with the advent of their Facebook Messenger app for iOS and Android and their acquisition of WhatsApp ${ }^{6}$ (Covert 2014), Facebook seems to be pushing their messaging service more in the direction of mobile-tomobile chat. They seem to be attempting to go in the direction of SMS texting; they created a standalone messaging mobile application called Messenger, and even went so far as to remove in-app messaging from the mobile Facebook application in Europe (Middleton 2014).

\section{The Who, What, and Why of Online Social Networking}

Online social networking websites are used worldwide by people from nearly every possible demographic. This paper focuses on the use of online social networking sites by

\footnotetext{
${ }^{6}$ WhatsApp is a mobile application for iOS and Android that allows users to chat SMS text-style internationally using data instead of SMS services. It was acquired by Facebook in 2014.
} 
Americans only. The Pew Internet and American Life Project estimates that as of September 2013, 73\% of American Internet users ages 18 and older use some form of online social networking. When that statistic is broken down further into more age groups, the numbers become even more striking: $90 \%$ of online Americans ages $18-29,78 \%$ of those ages $30-49$, and $65 \%$ of those ages 50-64 use at least one online social networking site (Pew Research Center 2013).

Those numbers haven't always been this high — this graph, also from the Pew Internet and American Life Project, shows the rapid adoption of online social networking by age group from 2005-2013.

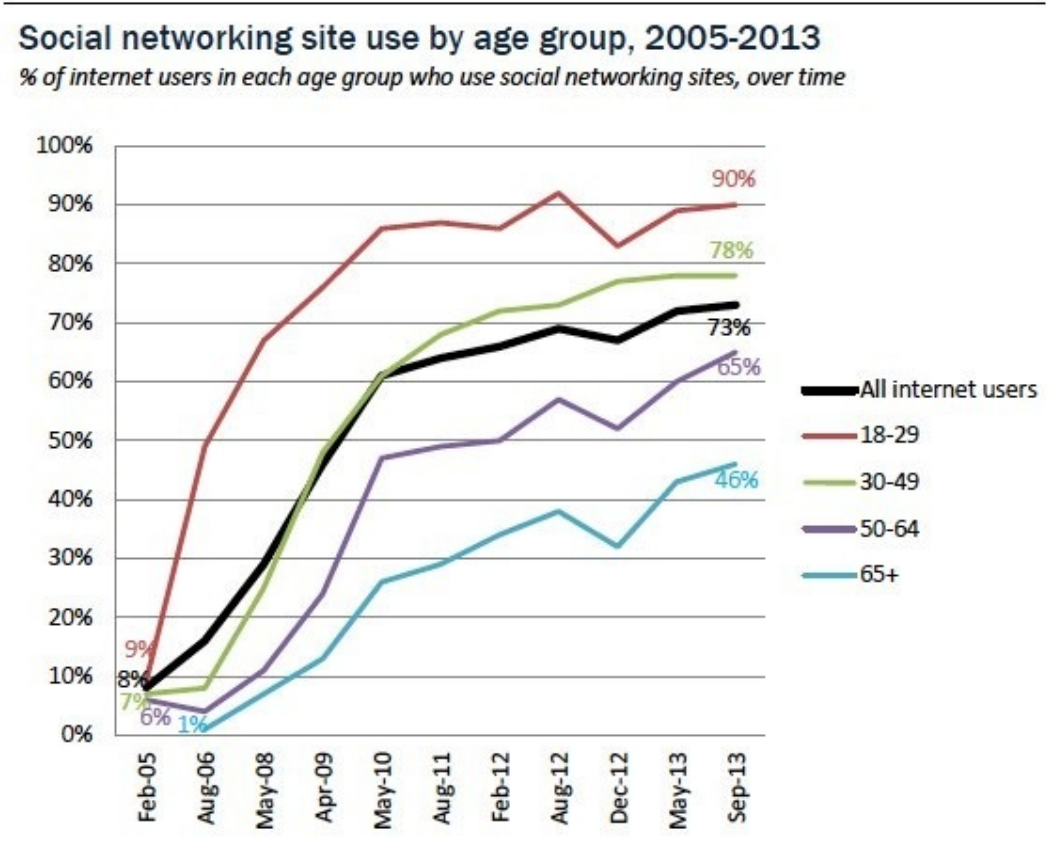

Source: Latest data from Pew Research Center's Internet Project Library Survey, July 18 - September 30 , 2013. N=5,112 internet users ages 18+. Interviews were conducted in English and Spanish and on landline and cell phones. The margin of error for results based on internet users is $+/-1.6$ percentage points.

As made clear by the graph, online social networking use has not always been as widespread as it is today. Most of this can be attributed to the fact that very few online social networking opportunities existed before 2005, and even then they were adopted more frequently 
by teens and young adults: see above, where the graph indicates that $9 \%$ of Internet users ages 18-29 used online social networking in 2005. The quick spread of online social networking site use can also be attributed to the more widespread availability of the Internet in everyday life; statistics from Pew Internet Research indicate that in 2014 86\% of American adults use the Internet, up from $14 \%$ in 1995 . The graph also indicates that though all age groups have grown in their use of online social networking, users 18-29 adopted the technology most rapidly. Older users did not take to online social networking as quickly, and still make up only slightly more than half of the adults using online social networking today.

Teens also make up a huge chunk of online Americans using online social networking platforms. As of 2012, 81\% of online teens and young adults ages 12-17 use some kind of online social media (Pew Research Group 2012). Teens were among the earliest adopters of online social networking to join sites like MySpace and LiveJournal en masse. As danah boyd writes, teens flocked to these online community spaces to express themselves to their friends (and Friends) in ways they may have felt stifled to do in their home or school environments. boyd sums up the popularity of MySpace among teens in the earlier mentioned piece Why Youth [Heart] Social Media: “...the popularity of MySpace is deeply rooted in how the site supports sociality among preexisting friend groups. Teens join MySpace to maintain connections with their friends."

Though boyd's quote, and piece in full, deal with the popularity of MySpace among teens, I would argue that the scale of that popularity is also applicable to Facebook. MySpace, launched in 2003, reached its peak popularity in 2008, at which point users began abandoning the site by the thousands. Much speculation surrounds the mass exodus from MySpace, and 
many scholars have theorized as to why the abandonment took place. In a 2007 report studying trends in teen use of MySpace, Patchin and Hinduja found that from 2006-2007, 9.9\% of the profiles they had used in their study had been deleted, and $37.4 \%$ of the profiles they used had been abandoned —not accessed at all since their 2006 coding until the time the study ended in 2007. Patchin and Hinduja hypothesized that this exodus occurred because users will only remain invested in an online social network if they have a sizable network of friends also active on the platform; the median number of friends, according to the authors, is 150 . Once users start to leave, other users' networks become smaller, and they begin to leave in exponential numbers. (Patchin \& Hinduja 2007). The reasons for the original users' abandonment vary, and research on this topic leaves much to be desired. In the future, research on the reasons why users abandon online social networks would be important to the literature on online social networks. In the meantime, I was able to track down a few user responses online — users seemed to complain that MySpace became too customizable, and therefore more difficult to use and difficult to glean information from.

The time teens began to abandon their MySpace profiles lines up fairly neatly with the time Facebook began allowing high school students, and eventually anyone over the age of 13 with an email address, to create Facebook profiles. Unlike MySpace, Facebook is not customizable in terms of how a user's profile appears to others, making it easy and intuitive for all users to design and read. It also makes the site more consistent and easily navigable for users less familiar with technology—i.e. the parents and grandparents of teens that left MySpace for Facebook. 
Teens tend to use online social networking sites to share photos and updates about their lives with real-life acquaintances and friends that they often see in daily life, in settings like school or extracurricular activities. They use online social networking sites as platforms to communicate with their friends, sometimes letting Facebook-mediated communication replace SMS texting, and more often turning to it rather than making an actual phone call. With technological advances in handheld devices, accessing Facebook at any moment from any location has become extremely easy, making synchronous communication between users viable.

Young adults, approximate ages 18-29, are unique in that they use SNS services to actually meet people for the first time online. Dating websites like OKCupid and mobile applications have grown in popularity alongside Facebook, enabling users to more easily and safely meet romantic prospects. This age group tends to use Facebook to document exciting experiences of their everyday lives; they are more likely to share photos of an event they attended than use the service as a main way to keep in touch with family.

Adults (approximate ages 30-49) have their own reasons behind using online social networking. According to Schwartz et al, adults that have established families and careers tend to use online social networking to share their accomplishments and life milestones with family members who use the SNS, Friends that they have reconnected with as a result of online social networking, or real-life acquaintances from their social circles in places like work and their children's school.

Older users of online social networking — the Boomer generation—make up the smallest portion of adult SNS users, but also show the fastest growth in the rate at which they are adopting online social networking tools. This generation tends to use online social networking to 
reconnect with people from their pasts, a concept encouraged early-on by the SNS Classmates. Past that, the older generation using Facebook uses it as a tool to keep in touch with younger family members.

By far, the preferred online social network of all users is Facebook. For the purposes of this paper, online social networks have been referred to in general, but most of the research and analysis has been pertaining to Facebook. As one of the older, and most widely used online social networking sites, more research exists about Facebook than other, newer online social networks with different focuses, such as Instagram or Twitter. 2014 statistics from the Pew Research Center indicate that $57 \%$ of all American adults and $73 \%$ of Americans ages $12-17$ use Facebook. Among adults, 64\% visit Facebook on a daily basis; an increase from 2010's measure of $51 \%$.

However, some research suggests that younger users are abandoning Facebook in favor of other social networks. Much of the speculation as to why teens and young adults are abandoning or deleting their Facebook accounts has to do with the fact that their parents and other older relatives are most likely quite involved on Facebook as well. Professor Daniel Miller of the University College London, speaking with the Guardian, says “...the most seminal moment in a young person's decision to leave Facebook was surely that dreaded day your mum sends you a friend request" (Kiss 2013). This correlates with danah boyd's hypotheses about teen and young adult use of SNSs - that they use SNSs to communicate with their friends and express themselves without the threat of parental intervention. As older family members become more active, as Dr. Miller continues, “...the children now say it is their family that insists they stay there and post about their lives" (Kiss 2013). It could be argued that due to the changes in family 
dynamics on SNSs, communication is significantly impacted. Research on the differences in registers used on Facebook, dependent on the relationship between the interlocutors, would be extremely valuable.

\section{Language as a Function of Age}

Before exploring language use by different age groups on social media, one must delve into the research that came before: language use by different age groups in general. The scope of this paper is such that this topic cannot be exhaustively covered, but it is important to consider the basic facts of language change with age before applying those facts to the relatively uncharted territory of age-related language use differences on online social networking websites.

It is useful to begin thinking about language as a function of age by briefly discussing the linguistic concept of age-grading. At its basest definition, age-grading is the phenomenon of individuals changing their linguistic behavior throughout their lifetimes, while the linguistic behavior of the community as a whole stays the same. The term was first introduced in 1950 by anthropologist Charles Hockett, but the current working definition comes from sociolinguist William Labov.

In 2003, scholars James Pennebaker and Lori Stone of University of Texas at Austin published an article detailing two projects undertaken to determine if and how an individual's language use changes over their lifespan. A few years earlier, Pennebaker created a computerized text-analysis program called Linguistic Inquiry and Word Count (LIWC), which he and Stone used in one study to analyze written and spoken samples from over 3000 participants of varying age, and in the other study to analyze the collected works of 10 different well-known writers 
(Pennebaker \& Stone, 2003). With the help of LIWC, Pennebaker and Stone analyzed this data for change as a function of age in 14 different text dimensions. Pennebaker and Stone presented 4 hypotheses in their article for how age would determine language use: 1) that with age would come drops in negative affect words and a slight increase in positive affect words; 2) that with age there would be a drop in social words and first person pronoun use; 3) that with age, users would experience a shift in concentration from the past tense to the present and future tenses, and 4) that with age people would use fewer cognitively complex words. Both of the studies undertaken by Pennebaker and Stone resulted in evidence favoring their hypotheses.

An important distinction to make when considering the differences in language between younger and older age groups online is the concept of "digital natives," popularized in an essay by Marc Prensky in 2001. Prensky's argument is that the students of today “think and process information fundamentally differently from their predecessors" due to the fact that they have been inundated with technology from birth (Prensky 2001). Indeed, Internet and SNSs users of the "Millennial" or "Generation X" age groups were introduced far earlier to computer-mediated communication than their older counterparts, which Prensky refers to as "digital immigrants." Younger users learned to exist in the "real" world and the digital world almost simultaneously, and thus learned to adapt their language to each situation. Language on the Internet has become fundamentally different from language in other corporeal written or spoken forms, and younger generations have witnessed those changes from within due to their early adoption of new technology. Older users, who didn't have access to these types of technologies during their formative years, sometimes find it more difficult to adapt and enmesh themselves into the online world. 
Prensky explains that the difference between being a digital native and a digital immigrant when it comes to language on Facebook or other SNSs can mean the difference between blending in and sticking out like a sore thumb. He refers to it as a "digital immigrant accent"-his examples include the need to print out documents in order to edit them, or using the Internet as a second choice to find information rather than going to it immediately. Prensky goes so far as to describe a digital immigrant's experience with learning how to use new technology as being like learning a new language. More literally, the language of digital immigrants online is noticeably different than the language of digital natives. This, too, can be attributed to what Prensky describes as the two generations being "socialized differently."

Putting the Pieces Together: Age, Language, \& Online Social Networking

As mentioned earlier, research on different age groups using online social networking websites is, frankly, lacking. This can be attributed to several factors. Online social networking is a relatively new activity. SNSs weren't introduced until the release of Friendster in 2002, and weren't widely acknowledged by a variety of ages and demographics until the rise of MySpace. At that point, teenagers and young adults were the major users of such platforms, and they were regarded by adults and seniors with a mixture of apathy ("this trend will pass") and trepidation at how youth were using these platforms. Adults, both those in middle-age and seniors, did not adopt SNSs as quickly as teenagers and young adults, and did not represent a significant population on SNSs until the last five years. 
A report from Schwartz et $\mathrm{al}^{7}$ in 2013 is arguably the most well-rounded piece today in terms of exploring the differences in language use between users of different age groups on online social networking platforms. Schwartz and his colleagues debrief, age group by age group (along with different personality types and genders), the language people use on Facebook, by analyzing a corpus of status updates. In addition to analyzing the language of status updates based on age, Schwartz et al worked to analyze differences in status updates based on personality type (measured by surveys of users included in their dataset) and gender. The dataset that Schwartz and his colleagues used, as they describe it, sounds optimal for measuring the differences in language in status updates due to age, gender, and personality: the data consisted of 19 million status updates, created by approximately 136,000 users. The users volunteered through using an outside application called My Personality, which gave them sets of questions to answer to determine their personality type, along with asking them for information on their age and gender. To be included in the study, they must have indicated English as their primary language and written at least 1000 words in status updates over their time using Facebook. Users included must have also indicated that their age was less than 65 , to avoid a non-representative sample of users over 65 (Schwartz et al 2013).

Schwartz et al used a combination of an open-vocabulary approach, called differential language analysis, and the LIWC (Linguistic Inquiry and Word Count) software (mentioned earlier in this thesis used by Pennebaker et al) to analyze language features that were specific to particular age groups, genders, or personality types. By using both methods, they attempted to 
recreate traditional language analyses based on different qualities of the speakers/writers (LIWC) but also to show that open-vocabulary approaches yield important insights ${ }^{8}$.

Schwartz et al's results show that older individuals on Facebook — the smallest group of users, but the fastest growing — tend to use more plural pronouns in their writing. One could assume that this is due to the fact that many older adults have spouses or families, and then use Facebook to update their Friends on the happenings with the whole family. Older individuals also tend to use more future tense verbs over past or present. This could be interpreted as this generation being prone to plan things for the future rather than focus on what's currently going on in their lives. It could also be argued that due to their use of more future tense verbs, they are less concerned with sharing details about their everyday lives and prefer to share possibilities for the future, perhaps to hold their audience's attention.

According to Schwartz et al, older users of Facebook also tend to use fewer selfreferences in their status updates, instead favoring talking about other people. This contrasts with findings in the status updates of younger users, who used significantly more self-references. This data could be used to speculate that users simply become less selfish as they age; younger users are more concerned with sharing information directly related to themselves, whereas older users tend to share about other people in their lives.

Schwartz et al's results found that older individuals tend to use more positive emotion words, and less negative emotion words, than younger age groups. This suggests that older users are happier in their lives than younger users, or perhaps that older users are just more willing to share about their good fortune than younger users. Though it crosses slightly more into the realm

\footnotetext{
${ }^{8}$ See Appendix I for an example of the word clouds generated by Schwartz et al's open vocabulary approach combined with the LIWC method.
} 
of psychology, it's important to note these differences in an analysis of language in Facebook status updates.

The last key difference Schwartz et al noted in the status updates of older users is that there was less stylistic use of negation. In this case, stylistic use of negation refers to a user implementing different ways to negate an idea; this could include use of a double negative, slang, etc. I would speculate that older users tend not to use stylistic negation as much as younger users due to a lack of familiarity with the differences between written language online and written language on other, more corporeal platforms.

When it came to younger individuals in their data pool, Schwartz et al were able to draw defined lines in vocabulary and topics chosen by younger age groups. Younger groups tended to use more slang, "Internet speak," commonly defined as acronyms and phonetic spellings that can make typing faster, and emoticons such as ":)" or ":(" to denote happy or sad feelings. These characteristics were by far more common among the youngest users to be included in this data set than in any other age group. In addition, it is in these sorts of characteristics-popular modern slang, different ways of typing online, and emoticons - that make up perhaps the biggest differences in the ways young adults and teens communicate via SNSs in contrast to older age groups. These differences stem from younger users being familiarized with technology, and how best to communicate via the Internet for maximum understanding and acceptance by other users, from a young age.

Schwartz et al also found distinct trends and progressions in topics in younger age groups. High school age users were found to have a large and distinct school-related topic reoccurring in their status updates; common vocabulary words included "school," "homework," 
and other related words. The topics changed and progressed in different age groups; college-age users had a distinct college-related topic that came up frequently, with vocabulary words like "register," "semester," and "college" being used regularly. College-age users were also more likely to post about alcohol— but in different ways, and with different vocabulary, than older users. Words like "drunk" and "wasted" tended to show up in the status updates of college-age users, compared to words like "beer" and "ale" in the status updates of 23-29 year olds.

An interesting finding that Schwartz et al bring up is that the topic of family-including vocabulary such as "daughter," "sister," "mother," etc.—grows in number of mentions correlated to higher age of the user. In conjunction with this, the number of self-references ("I") decrease with age after the age of 22, while "we" increases linearly. For a visual look at the topics and vocabulary Schwartz et al were able to designate to each age group, see the word clouds in the appendix.

Part of the reason Schwartz et al undertook this study was to determine how language data as it applies to the differences in age, gender, and personality of the user could be used to create predictive models based on language. Schwartz et al argue that their method of differential language analysis is actually an "unobtrusive" way to acquire information about users. The authors of this study explore these predictive models more for the sake of experimentation and research on the model rather than applying the models to any other purpose. The field of predictive models for language is still a burgeoning one; the technology is young and hasn't been fully developed. There is plenty of room for future research on the topic of predictions based on language, and the applications of these models are numerous. 


\section{Teens}

As mentioned several times throughout the course of this paper, danah boyd is one of the most prominent researchers in the field of media studies today. Though boyd's research isn't explicitly tied to language use on SNSs, her work is important and enlightening to the ways that teenagers self-identify and communicate using online social networking. Much of her research comes in the form of ethnographic interviews, in which she delves into teenagers' online habits and personal doctrine on how to exist within and communicate on SNSs. Some of boyd's most prominent research is on the topic of privacy within the online "public" of SNSs, and how the perception of privacy differs with age. In her pieces, particularly Why Youth [Heart] Social Media and her recent book It's Complicated: The Social Lives of Networked Teens, she details the dilemma of $21^{\text {st }}$-century parenting, in the age of online social networking. Kids can't play outside in the "dangerous" world anymore, and thus turn to the online world to socialize with their peers. boyd's research ties into the argument that teens and young adults use language on SNSs in fundamentally different ways than older age groups. In the early days of instant messaging and chatrooms, "chatspeak" became commonplace, and for some parents, a cause for worry that their children were trying to hide things from them. It was a fundamental difference in the way teens and adults communicated online — and due to its unfamiliarity, it was frightening. Teens, argues boyd, were simply finding ways to more easily communicate with one another. In addition, they wanted to keep that communication private.

Though his work came somewhat earlier than boyd's, Guy Merchant's piece Teenagers in cyberspace: an investigation of language use and language change in internet chatrooms reinforces the hypothesis that teens are at the forefront of linguistic innovation online. One of 
Merchant's arguments is that the style of typing that seems unique to teens- "chatspeak"actually developed as instant messaging became closer to actual speech. From his paper:

The use of 'u', 'wot' and 'woz,' help us read this 'as speech'. The use of 'u,' 'wot' and 'woz,' like the lower case ' $i$ ' and 'ok' save typing time and increase the pace of the dialogue, and possibly suggest an informality that approximates to speech. (Merchant 2001)

\section{Future Research}

One of the things I hope has been clear throughout the course of this paper is that the skeleton of linguistic research in online social networking as it pertains to age has been built. The authors I've cited have begun the task of documenting the differences in age groups and have begun to speculate why those differences exist. However, the field is still growing, and the work is far from over. In the future, more research must be done in the field of language use on online social networking sites in general.

In addition to linguistic research, more research needs to be done on the psychological implications of frequent use of online social networking platforms in different age groups. Though Facebook and other SNSs are meant to be community-minded places where users can communicate and keep in touch with one another, they can be extremely isolating places. In surveys from the Pew Research Center and other organizations, users have frequently cited feeling "left out" when they see pictures of events they weren't invited to-a phenomenon that has become known as FOMO ("fear of missing out") in the media. 
To briefly return to the Schwartz et al piece I analyzed earlier, I think that more research is needed — and will undoubtedly be conducted — on the topic of using language analysis to create predictive models. In a real-world application, these predictive models could be immeasurably useful in online marketing situations; if, like in the Schwartz et al dataset, users consented to their language being analyzed, companies would then be able to very effectively target products toward a particular age group, gender, or personality type without actually asking for too much personal information from the user. This, of course, raises ethical questions that this thesis doesn't have the scope to cover. It could be argued that using predictive models such as Schwartz et al suggest could be an invasion of privacy.

This thesis should prove that research specifically relating linguistics and language use to online social networking platforms is a small field, and decidedly hard to find. Large-scale studies of how language structure affects the formation of relationships and communities online would be extremely valuable to the field of media studies. Due to the rapid change inherent to the Internet and SNS use, longitudinal studies of user interaction and language use would be interesting to see.

\section{Conclusion}

It is difficult to attempt to conclude a thesis that merely serves as a review of current literature. In the case of this topic_-language use among different age groups on Facebook, and other SNSs - the field of research simply changes too quickly to ever truly stay on top of it. This thesis serves as a snapshot of what the world of language on online social networking platforms, and its quirks and implications, was like at its roots up until the present. In the grand scheme of 
things, technology grows, adapts, and changes virtually at the speed of light. In turn, users grow, adapt, and change with it. Following that track, the language used changes as well.

However, even when technology changes and users change with it, there are vestiges of how that user learned to use technology in the first place. Going back to Prensky, digital immigrants always have "...their foot in the past" (Prensky 2001). When it comes to online social networking, users will always have different prerogatives; those could be determined by their age, personality, gender, and countless other factors. In addition, the ways people use online social networking platforms, and their reasons for doing so, will change as quickly as the makeup of the technology that supports them. No matter the technology, it is our generation, our age, and our upbringing that determine the way we will use language online. 


\section{References}

Barker, V. (2012). A generational comparison of social networking site use: The influence of age and social identity. The International Journal of Aging and Human Development, 74(2), 163-187. doi:10.2190/AG.74.2.d

Barnett, E. (2011, January 6). MySpace by numbers: How it compares to its rivals. The Telegraph [Kent, UK.]. Retrieved from http://www.telegraph.co.uk/technology/ myspace/8243403/MySpace-by-numbers-how-it-compares-to-its-rivals.html

Boyd, D., \& Ellison, N. B. (2007). Social network sites: Definition, history and scholarship. Journal of Computer-Mediated Communication, 13(1), 210-230.

Boyd, D. (2006). Friends, Friendsters, and Top 8: Writing community into being on social network sites. First Monday. Retrieved from http://www.danah.org/papers/ FriendsFriendsterTop8.pdf

Boyd, D. (2007). Why youth (heart) social network sites: The role of networked publics in teenage social life. Retrieved from Social Science Research Network website: http://papers.ssrn.com/abstract $=1518924$

Caers, R., De Feyter, T., De Couck, M., Stough, T., Vigna, C., \& Du Bois, C. (2013). Facebook: A literature review. New Media \& Society, 15(6), 982-1002.

Constine, J. (2011, January 12). Facebook returns "what's on your mind?" prompt to the home page - Inside Facebook [Web log post]. Retrieved from http:// www.insidefacebook.com/2011/01/12/whats-on-your-mind-home-page/

Crystal, D. (2001). Language and the Internet. Cambridge: Cambridge University Press. 
Danescu-Niculescu-Mizil, C., West, R., Jurafsky, D., Leskovec, J., \& Potts, C. (2012). No country for old members: User lifecycle and linguistic change in online communities. Retrieved from International World Wide Web Conferences Steering Committee website: http://www.stanford.edu/ jurafsky/pubs/ linguistic_change_lifecycle.pdf

Divita, D. (2012). Online in later life: Age as a chronological fact and a dynamic social category in an Internet class for retirees. Journal of Sociolinguistics, 16(5), $585-612$.

Facebook (2012, January 24). Timeline now available worldwide. Retrieved May 14, 2014, from https://www.facebook.com/notes/facebook/timeline-now-availableworldwide/10150408488962131

Facebook (2014, February). What does it mean to "Like" a page or content on Facebook? Retrieved May 14, 2014, from https://www.facebook.com/help/ 131263873618748

Facebook (2014, February). What does it mean to "Like" something? | Facebook. Retrieved May 14, 2014, from https://www.facebook.com/help/110920455663362 Hampton, K. N., Goulet, L., Rainie, L., \& Purcell, K. (2011). Social networking sites and our lives. Retrieved from Pew Internet \& American Life Project website: http://www.pewinternet.org/Reports/2011/Technology-and-social-networks.aspx Hargittai, E., \& Hinnant, A. (2008). Digital inequality: Differences in young adults' use of the internet. Communication Research, 35(5), 602-621. doi: $10.1177 / 0093650208321782$ 
Hockett, C. (1950). Age-grading and linguistic continuity. Language, 26(4), 449-457. Retrieved from http://www.jstor.org/stable/410396

Kern, M. L., Eichstadt, J. C., Schwartz, A. H., Park, G., Ungar, L. H., Stillwall, D. J., . . . Seligman, M. E. (2014). From "sooo excited!!!!!!" to "so proud:" Using language to study development. Developmental Psychology, 50(1), 178-188. doi:10.1037/ a0035048

Kiss, J. (2013, December 27). Teenagers migrate from Facebook as parents send them friend requests. The Guardian [London]. Retrieved from http:// www.theguardian.com/technology/2013/dec/27/facebook-dead-and-buried-toteens-research-finds

Kleinrock, L. (2008). History of the Internet and its flexible future. IEEE Wireless Communications, 15(1), 8-18.

Labov, W. (1992). Principles of linguistic change. Oxford, UK: Blackwell.

Madden, M. (2010). Older adults and social media. Retrieved from Pew Internet \& American Life Project website: http://pewinternet.org/Reports/2010/Older-Adultsand-Social-Media.aspx

Maíz-Arévalo, C., \& García-Gómez, A. (2013). ‘You look terrific!' Social evaluation and relationships in online compliments. Discourse Studies, 15(6), 735-760. doi: $10.1177 / 1461445613490011$

Merchant, G. (2001). Teenagers in cyberspace: an investigation of language use and language change in internet chatrooms. Journal of Research in Reading, 24(3), 293. 
Middleton, J. (2014, April 11). Facebook kills app messaging in Europe to push standalone Messenger [Web log post]. Retrieved from http://www.telecoms.com/ 246012/facebook-kills-app-messaging-in-europe-to-push-standalone-messenger/

Mitchell, J. (2010, December 15). Making photo tagging easier. Retrieved May 14, 2014, from https://www.facebook.com/notes/facebook/making-photo-taggingeasier/467145887130

Patchin, J. W., \& Hinduja, S. (2010). Trends in online social networking: adolescent use of MySpace over time. New Media \& Society, 12(2), 197-216.

Pennebaker, J. W., \& Stone, L. D. (2003). Words of wisdom: Language use over the life span. Journal of Personality and Social Psychology, 85(2), 291-301.

Prensky, M. (2001). Digital natives, digital immigrants, part 1. On the Horizon, 9(5). doi:10.1108/10748120110424816

Raice, S., \& Ante, S. E. (2012, April 12). Facebook to buy Instagram for \$1 billion. Wall Street Journal [New York]. Retrieved from http://online.wsj.com/news/articles/ SB10001424052702303815404577333840377381670

Schwartz, H. A., Eichstadt, J. C., Kern, M. L., Dziurzynski, L., Ramones, S. M., Agrawal, M., .. . Ungar, L. H. (2013). Personality, gender, and age in the language of social media: The Open-Vocabulary Approach. PLoS One, 8(9). Retrieved from http://dx.doi.org/10.1371/journal.pone.0073791

Smith, A. (2013, December 30). Social media update 2013 | Pew Research Center's Internet \& American Life Project [Web log post]. Retrieved from http:// www.pewinternet.org/2013/12/30/social-media-update-2013/ 
Soar, D. (2011, October 24). What does it really mean to Like something on Facebook? Brandwatch [Web log post]. Retrieved from http://www.brandwatch.com/2011/10/ what-does-it-really-mean-to-like-something-on-facebook/

Stroud, D. (2008). Social networking: An age-neutral commodity — Social networking becomes a mature web application. Journal of Direct, Data and Digital Marketing Practice, 9(3), 278-292.

Wilson, R. E., Gosling, S. D., \& Graham, L. T. (2012). A review of Facebook research in the social sciences. Perspectives on Psychological Science, 7(3), 203-220.

Wormald, B. (2013, December 12). Social media use over time | Pew Research Center's Internet \& American Life Project [Web log post]. Retrieved from http:// www.pewinternet.org/data-trend/teens/social-media/

Wormald, B. (2013, December 17). Social media user demographics | Pew Research Center's Internet \& American Life Project [Web log post]. Retrieved from http:// www.pewinternet.org/data-trend/social-media/social-media-user-demographics/

Zickuhr, K., \& Madden, M. (2012). Older adults and internet use. Retrieved from Pew Internet \& American Life Project website: http://pewinternet.org/Reports/2012/ Older-adults-and-internet-use.aspx 
Appendix I

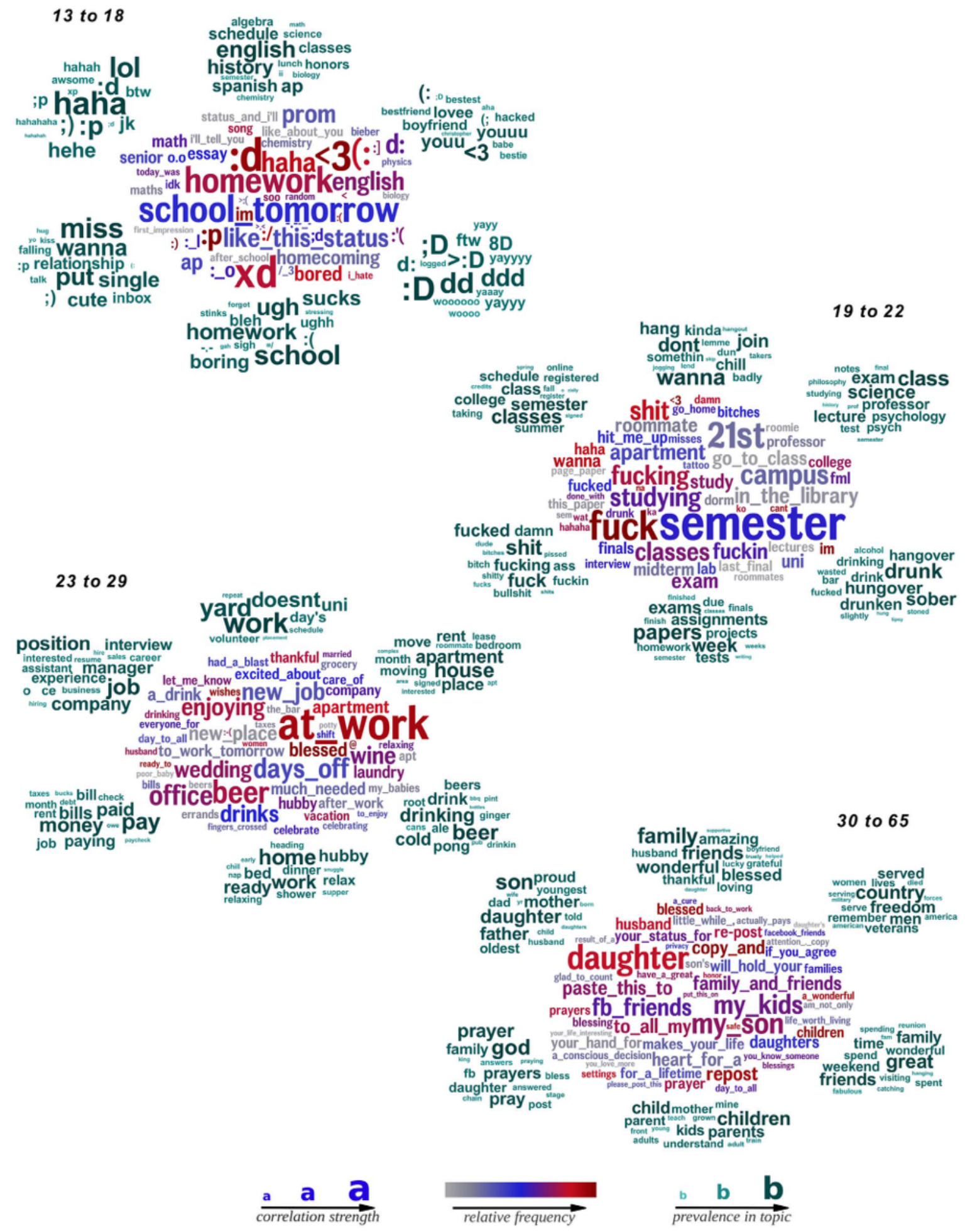

